\title{
Role of the Resid Solvent in Catalytic Coprocessing with Finely Divided Catalysts
}

\section{Quarterly Report}

\author{
April to June 1995
}

\section{Contract No. DE-AC22-91PC91055}

\section{DISCLAIMER}

This report was prepared as an account of work sponsored by an agency of the United States Government. Neither the United States Government nor any agency thereof, nor any of their employees, makes any warranty, express or implied, or assumes any legal liability or responsibility for the accuracy, completeness, or usefulness of any information, apparatus, product, or process disclosed, or represents that its use would not infringe privately owned rights. Reference herein to any specific commercial product, process, or service by trade name, trademark, manufacturer, or otherwise does not necessarily constitute or imply its endorsement, recommendation, or favoring by the United States Government or any agency thereof. The views and opinions of authors expressed herein do not necessarily state or reflect those of the United States Government or any agency thereof.

\section{Christine W. Curtis}

Chemical Engineering Department Auburn University, Alabama 36849-5127 


\section{Acknowledgements}

The experimental work of Mr. Jing Shen and Mr. Charles J. Brannan is gratefully acknowledged. The assistance of Mr. Henry Cobb and Mr. Michael Hornsby is sincerely appreciated. The word processing assistance of Mrs. Melanie Butcher is also sincerely appreciated. 


\section{Table of Contents}

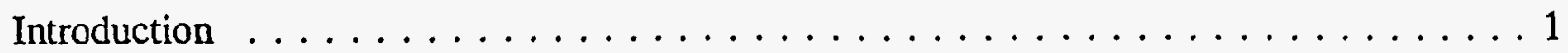

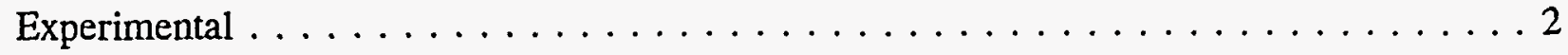

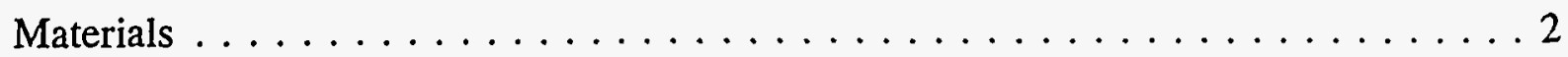

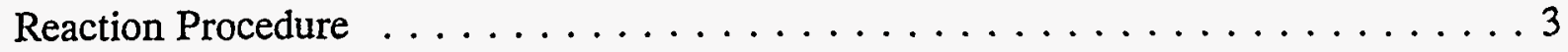

Gas Chromatographic Analysis . . . . . . . . . . . . . . . 4

Calculations $\ldots \ldots \ldots \ldots \ldots \ldots \ldots \ldots \ldots \ldots \ldots \ldots \ldots \ldots \ldots \ldots \ldots \ldots \ldots \ldots \ldots$

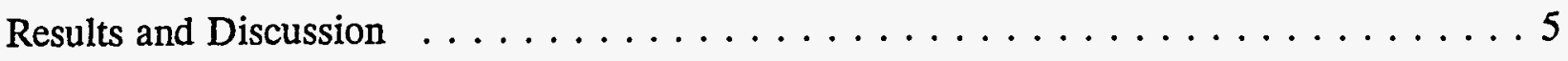

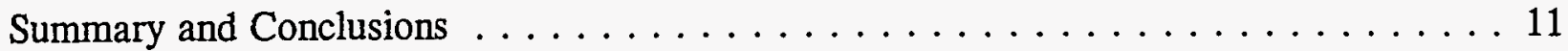

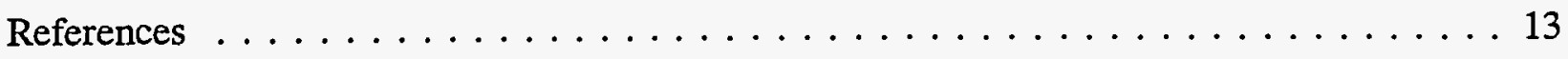




\section{Introduction}

The research reported in this progress report describes the continuation of coal-resid coprocessing reactions that were discussed in the January to March 1995 Quarterly Report. During previous quarters, Maya and FHC-623 resids were evaluated in non-catalytic and catalytic reactions at $400^{\circ} \mathrm{C}$ with Pittsburgh No. 8 and DECS -17 Blind Canyon coals. From the complete reaction matrix containing the two coals and two resids, it was found that the influence of resids on coprocessing depended on the type of coal used; for example, under catalytic reaction conditions, the hexane solubles of Maya resid increased coal conversion of Pittsburgh No. 8 coal but decreased that of DECS-17. In order to observe the intrinsic behavior of resids during coprocessing, another resid, Manji, and another coal, Illinois No. 6, are being tested. These reactions were begun this quarter. The results obtained are reported herein.

In order to evaluate the role of the different components in resids, the resids were separated into hexane soluble materials and hexane insoluble materials. The hexane solubles, which should contain the naphthenes present in the resid, and the untreated whole resids were reacted with coal at equivalent liquefaction conditions and at the same conditions as when the resids were reacted individually.

In the catalytic reactions, a Mo naphthenate catalyst precursor was used in the presence of excess, elemental sulfur. The catalyst generated in situ was $\mathrm{MoS}_{2}{ }^{1}$. The effect of the reaction system on coal behavior during liquefaction was determined by coal conversion to THF solubles and solvent fractionation of the reaction products. Simulated distillations could not be performed this quarter because the laboratory was flooded from an overhead pipe that burst twice. The gas chromatograph, computer, and integrator were drenched twice with cold water. The equipment is now undergoing repair. 


\section{Experimental}

Materials. The materials used during the quarter were Maya and Manji resids which were supplied by Amoco. The resids were used as whole resids or as the hexane soluble fractions of the resids in the reactions performed. The resids were dissolved in hexane and the hexane phase was decanted separating the hexane solubles from the hexane insolubles. In Table 1, the resids were fractionated into three solvent fractions: hexane solubles; toluene solubles, hexane insolubles; toluene insolubles, THF solubles; and THF insolubles or IOM which is insoluble organic matter and is ash free. The coprocessing solvents fractionated from the three solvents were quite different from one another. The two resids, FHC-623, which was used previously, and Manji were similar in solubility fraction contents, but these two resids contained less toluene solubles and more hexane solubles than did Maya resid as shown in Table 1.

The solvent fractionation procedure performed on the three resids involved dissolving $10 \mathrm{~g}$ of each resid in $150 \mathrm{ml}$ of hexane and sonicating for $15 \mathrm{~min}$. The sample was then centrifuged for $30 \mathrm{~min}$ and the hexane solubles were decanted from the hexane insolubles. Another $150 \mathrm{ml}$ of hexane were added to the insolubles and the procedure was repeated a second and third time. The remaining solids were subjected to fractionation by toluene and THF sequentially following the same procedure as was used for hexane. The toluene solubles, hexane insolubles and THF solubles, toluene insolubles fractions were obtained along with the THF insolubles. The solvents used in this study were hexane, toluene and THF; all of which were HPLC grade and obtained from Fisher Scientific Co.

The coals used in this study were Pittsburgh No. 8 and Illinois No. 6 bituminous coals which were obtained from the Argonne Premium Coal Sample Bank and Blind Canyon (DECS-17) 
bituminous coal was obtained from the Penn State Coal Sample Bank. The coal particle size was 200 mesh. Proximate and ultimate analyses for the three coals are presented in Table 2.

The catalyst precursor used in this study was molybdenum (Mo) naphthenate, a slurry phase catalyst precursor. Molybdenum naphthenate was obtained from Shepherd Chemical and contained $6 \mathrm{wt} \% \mathrm{Mo}$. The Mo naphthenate slurry phase catalyst was reacted in the presence of excess, elemental sulfur which was obtained from Aldrich.

Reaction Procedure. The reactions performed involved the reaction of resids with coal under non-catalytic and catalytic conditions. All of the reactions were performed in stainless steel tubular microreactors of $\sim 20 \mathrm{~cm}^{3}$ volume. For each reaction, approximately $1 \mathrm{~g}$ of resid (weighed accurately to $0.0001 \mathrm{~g}$ ) dissolved in $3 \mathrm{ml}$ of THF was introduced into the reactor. The THF was evaporated by placing the microreactor in a vacuum oven overnight; coal was added to the system after the THF evaporated. In the catalytic reactions, Mo naphthenate was introduced at a loading of 1000 ppm Mo on total reactor charge. Elemental sulfur was added to the reactor at $3: 1 \mathrm{~S}$ to Mo stoichiometric ratio assuming that $\mathrm{MoS}_{2}$ was produced from Mo naphthenate.

The microreactor was pressurized with hydrogen three times to purge any air present. A hydrogen pressure of $8.7 \mathrm{MPa}$ at room temperature was introduced for the reaction. The reaction conditions were $400^{\circ} \mathrm{C}$ for $30 \mathrm{~min}$ with horizontal agitation of $400 \mathrm{cpm}$. After the reaction was completed, the tubular microreactor was immersed in cold water immediately quenching the reaction. All of the reactions were duplicated. The reaction products were removed from the reactor by washing the microreactor with several $10 \mathrm{ml}$ aliquots of THF. The sample was then stored in a vial for further analysis. The reaction products dissolved in THF were subjected to gas chromatographic analysis to evaluate the temperature distribution of the resid products. The 
recovery of the reaction products was achieved by evaporating the THF solvent and drying the products in an oven overnight at $50^{\circ} \mathrm{C}$.

Gas Chromatographic Analysis. The reaction products were analyzed using a Varian 3300 gas chromatograph equipped with a $25 \mathrm{~m}$ fused silica HT-5 capillary column and FID detection. For analysis of the resid reaction products, a temperature program starting at $100^{\circ} \mathrm{C}$ increasing to $320^{\circ} \mathrm{C}$ at a program rate of $2.5^{\circ} \mathrm{C} / \mathrm{min}$ was used. The GC output was automatically recorded and stored in a computer using a software named Peak96 from Hewlett Parkard. (Simulated distillation was not performed during this quarter).

Calculations. The calculations performed to describe the coprocessing reactions are given in the following:

$$
\text { conversion }=\left(1-\frac{g(\text { IOM })_{\operatorname{maf}}}{g(\text { coalcharged })_{\operatorname{maf}}}\right) \times 100 \%
$$

where IOM is the insoluble organic material and maf is moisture and ash free.

For Pittsburgh No. 8 as described in Table 2, the simplified equation is

$$
\text { conversion }=\left(1.102-1.20 \times \frac{g(\text { IOM })}{g(\text { coalcharged })}\right) \times 100 \%
$$

For Blind Canyon DECS-17, the simplified equation is:

$$
\text { conversion }=\left(1.070-1.112 \times \frac{g(\text { IOM })}{g(\text { coalcharged })}\right) \times 100 \%
$$

For Illinois No. 6 coal, the simplified equation is:

$$
\text { Coal conversion }=\left(1.183-1.286 \times \frac{g(\text { IOM })}{g(\text { coalcharged })}\right) \times 100 \%
$$




\section{Results and Discussion}

The research performed this quarter focused on coprocessing a highly reactive coal, Illinois No. 6, bituminous with FHC-623 and Manji whole resid, hexane solubles fraction and saturate fraction and with the hexane soluble fraction of Maya resid (Table 3). As mentioned in the last quarterly report the selection of the third coal was prompted by the different reactivities exhibited by Pittsburgh No. 8 and Blind Canyon DECS-17 coals when these coals were reacted with Maya and FHC-623 resids.

Manji resid was also introduced into the sample matrix since the other two resids were quite different in composition and gave substantially different results when they were reacted with the same coals. A compilation of the coprocessing reactions performed to date with Manji resid are given in Table 4.

Previous results using Maya and FHC-623 resids showed that the interaction between resid and coal was affected by the composition of the resid or resid fraction. For example, the saturate fraction of Maya resid when reacted with Pittsburgh No. 8 coal resulted in decreased conversion to THF solubles, but when the Maya saturates were reacted with Blind Canyon coal, coal conversion to THF solubles increased. These two coals showed substantial differences in their inherent reactivity; Pittsburgh No. 8 was much more reactive than Blind Canyon coal under equivalent reaction conditions and when the same type of resid solvent was used. Using a highly reactive coal such as Illinois No. 6 may provide valuable information concerning the intereactions between the various resid fractions and coal.

Thermal and catalytic reactions performed last quarter used hexadecane, Maya whole resid and Manji hexane solubles as the solvents. The catalyst was slurry phase Mo naphthenate and excess 
sulfur. Thermal and catalytic reactions of coal alone yielded similar results and low conversion of coal to THF solubles. Addition of hexadecane to coal matrix containing slurry phase catalyst helped to disperse the slurry phase catalyst in the reaction matrix and resulted in increased conversion of coal to THF solubles.

Coprocessing Reactions with Mlinois No. 6 Coal. The coprocessing reactions of Illinois No. 6 coal with resids and resid fractions are presented in Table 3. The reactions performed this quarter included coprocessing reactions with whole FHC-623 resid and the hexane soluble and saturate fractions of FHC-resid, with whole Manji resid and the hexane soluble and saturate fractions of Manji resid, and the hexane soluble fraction of Maya resid. The catalytic reaction of Maya whole resid with Illinois No. 6 performed last quarter that was suspect was performed again and the results are given in Table 3. Comparing the amount of Illinois No. 6 coal conversion achieved in the thermal and catalytic reactions showed that the conversions achieved were very similar, although the catalytic reaction produced slightly higher conversion. Maya resid contains a high proportion of asphaltenes and a high metals ( $\mathrm{Ni}$ and $\mathrm{V}$ ) content. When the asphaltenes were removed from the Maya resid and the metals content was subsequently reduced, reaction of the hexane soluble fraction of Maya resid with Illinois No.6 coal promoted coal conversion to THF solubles in both thermal and catalytic reactions. The coal conversion increased from 61.4 to $69.0 \%$ in the thermal reactions and in the catalytic reactions even higher increases were realized as the coal conversion increased from 63.4 to $81.4 \%$. Since the removal of the asphaltene molecules from the whole resid positively affected the coprocessing reaction with Illinois No. 6 coal, the chemistry and composition of the asphaltenes in Maya resid were detrimental to both the thermal and catalytic reactions that occurred. 
The reactions of FHC-623 whole resid and hexane soluble resid fraction with Illinois No. 6 coal gave similar results as the reactions with Maya whole resid and hexane soluble fraction. The coal conversion in both the thermal and catalytic reactions increased with hexane soluble fraction compared to the whole resid. It is evident that when the asphaltene molecules were removed and the coking propensity and metals content was reduced, the reaction with Illinois No. 6 coal was enhanced. The increase realized when changing from whole FHC-623 resid to FHC-623 hexane solubles was less than that for Maya resid. The conversion achieved in the thermal reaction with the whole resid was $66.4 \%$ and with the hexane soluble fraction was $67.4 \%$. As with Maya resid the increase in the catalytic reaction with FHC-623 resid was greater; $70.2 \%$ conversion was obtained with the whole resid while $79.2 \%$ was obtained with the hexane solubles.

The reactions of Illinois No. 6 coal with Manji whole resid and resid fractions again showed that the coal-solvent interaction is unique and dependent on the chemistry of the system. Reactions of Illinois No. 6 coal with Manji whole resid yielded higher conversions in both thermal and catalytic reactions than the hexane soluble fraction. The asphaltenes in the whole Manji resid were not detrimental to the coprocessing reaction as compared to Maya or FHC-623 resids. The thermal reaction with the saturate fraction and Illinois No. 6 coal produced a coal conversion that was nearly equivalent to that obtained with thehexane soluble fraction. The catalytic reaction for the saturate fraction with Illinois No. 6 coal resulted in the highest conversion achieved with Illinois No. 6 coal.

Coprocessing Reactions with Manji Resid. The coprocessing reactions performed to date with Manji resid and Manji resid fractions are given in Table 4. Coprocessing reactions with the whole resid clearly demonstrated the differences in the reactivity between Pittsburgh No. 8 coal, 
Canyon DECS-17 coal, and Illinois No. 6 coal. Both the thermal and catalytic reactions showed that Pittsburgh No. 8 had a higher reactivity than Blind Canyon DECS-17 coal under these reaction conditions, while Illinois No. 6 coal had lower reactivity. The Mo naphthenate catalyst was highly effective for Pittsburgh No. 8 and Blind Canyon coals in Manji resid and resulted in a doubling of the coal conversion compared to the thermal reaction.

Coprocessing reactions of all three coals with Manji hexane solubles resulted in substantial differences in their conversion behavior in both thermal and catalytic reactions. For example, Pittsburgh No. 8 yielded much lower thermal coal conversion than either Blind Canyon DECS-17 or Illinois No.6 which were nearly equivalent in their thermal conversion behavior. By contrast, the catalytic conversion achieved with Mo naphthenate and sulfur was higher and nearly equivalent with Pittsburgh No.8 and DECS-17 coal while Illinois No. 6 coal was much lower. The Manji saturate fraction coprocessed with Pittsburgh No. 8 and DEC-17 coals tended to have a lower overall conversion than either of the other two Manji solvents. When coprocessed with Illinois No. 6 coal, Manji saturates exhibited a similar propensity for converting coal to THF solubles as did the Manji whole and hexane soluble fraction.

These results evince that several factors were affecting the coal conversion in these coprocessing reactions. These factors include the effect of the solvent on the particular coal reactions occurring. Asphaltenes present in resids appeared to be detrimental for the coals used; however, further removal of the aromatics from the resid was detrimental to the liquefaction process and resulted typically in lower conversion. The catalyst and its interaction with the coal and resid also affected the amount of conversion. Different coals responded differently to the catalyst. In the reactions using whole resides with lower catalytic conversion, the catalyst may 
have been poisoned by the composition of the materials that were present in the coprocessing system.

Evaluation of Hydrogen Transfer from Resids and Resid Fractions to Anthracene. In the above described coprocessing reactions, not only did the whole resids' or resid fractions' composition affect the amount of coal conversion, but the coal's chemistry and reactivity also affected the amount of coal conversion achieved. Therefore, the effect of the resid or resid fraction itself on converting coal was difficult to discern. And, since the resid or resid fractions may serve as both solvating agents and as hydrogen donors to coal, experiments were performed with the whole resid and resid fractions using anthracene as a model acceptor to evaluate the propensity of these resid solvents to transfer hydrogen under coprocessing reaction conditions. Reactions were performed with anthracene alone and with perhydropyrene plus anthracene and hexadecane plus anthracene. These reactions showed the effect of the reaction conditions as well as the effect of having an additional hydrocarbon species present in the reaction. Table 5 presents the $\mathrm{H}_{2}$ accepted by anthracene in thermal and catalytic reactions; $\mathrm{H}_{2}$ accepted is defined as the moles of $\mathrm{H}_{2}$ accepted per 100 moles of anthracene. Table 6 presents the anthracene product distribution from reactions with resid and resid fractions.

Thermal reactions of anthracene alone and with the resid, resid fractions and hydrocarbons resulted in less $\mathrm{H}_{2}$ being accepted by anthracene than in the catalytic reactions. The presence of MoNaph $+\mathrm{S}$ promoted hydrogenation of anthracene from molecular $\mathrm{H}_{2}$ as shown by the increase of moles of $\mathrm{H}_{2}$ accepted per 100 moles of anthracene from 104.3 to 123.2 when anthracene was reacted alone in molecular $\mathrm{H}_{2}$. The addition of a hydrocarbon solvent such as hexadecane or perhydropyrene decreased the amount of $\mathrm{H}_{2}$ accepted by anthracene. The straight chain hydrocarbon, hexadecane, decreased the amount of $\mathrm{H}_{2}$ accepted more than the naphthene, perhydropyrene. In fact, at a 1:1 ratio 
perhydropyrene only minimally reduced the amount of $\mathrm{H}_{2}$ accepted. Two obvious factors affected the amount of $\mathrm{H}_{2}$ accepted in these reactions: the diluent effect of adding a solvent and the amount of hydrogen that can be released from the solvent and donated to anthracene.

Introduction of Maya whole resid and resid fractions decreased the amount of $\mathrm{H}_{2}$ accepted in both thermal and catalytic reactions compared to the anthracene alone reaction and the anthracene with perhydropyrene reaction. However, the amount of $\mathrm{H}_{2}$ accepted was similar to that of the hexadecane reaction. For the Maya reactions, the whole resid and saturate fraction gave similar $\mathrm{H}_{2}$ accepted in the thermal and catalytic reactions with anthracene while the $\mathrm{H}_{2}$ accepted in the reactions with the hexane soluble fraction was less in the thermal reaction and more in the catalytic reaction than the other two resid materials. The FHC-623 whole resid and resid fractions gave very similar values for $\mathrm{H}_{2}$ accepted in the thermal and catalytic reactions.

The diluent factor that reduced the amount of $\mathrm{H}_{2}$ accepted was apparent in the addition of the whole resids and resid fractions to the anthracene reaction. The composition of the resids and the compatibility between the chemistry of the resid material and the catalyst were also factors that affected the amount of coal conversion achieved in these reactions.

The anthracene product distributions obtained in the reactions with the different resids and resid fractions are given in Table 6. The products that were obtained in these reactions were dihydroanthracene (DHA) and tetrahydroanthracene (THA) as well as some unreacted anthracene. The primary product was DHA regardless of the reaction condition, thermal or catalytic, or the type of solvent present. The catalytic reaction produced a higher amount of THA regardless of the donor solvent present; however, the amount of THA that was produced varied according to the type of solvent present. The reaction with perhydropyrene produced the most THA and had the 
least anthracene present of all of the reactions. With both Maya and FHC-623 the reactions with the hexane solubles produced the most THA. However, the difference in the amount of THA produced was substantially greater among the Maya whole resid and resid fractions than among the FHC-623 whole resid and resid fractions.

The moles of $\mathrm{H}_{2}$ accepted per 100 moles of anthracene followed the production of THA in these reactions. The amounts from the catalytic reactions were higher while those from the thermal reactions were lower. Reactions using hexane soluble fractions from both Maya and FHC-623 resids resulted in higher $\mathrm{H}_{2}$ acceptance by anthracene than either the whole resids or saturate fractions, although the whole resids donated more $\mathrm{H}_{2}$ that was accepted by anthracene than the saturate fractions.

\section{Summary and Conclusions}

A compilation of the thermal and catalytic coprocessing reactions performed to date is presented in Table 7. All of the thermal reactions converted less coal than the catalytic reactions. The different types of solvents used had varying effects on coal conversion depending on their composition and interaction with coal. Illinois No. 6 coal behaved differently from the other two coals when the same types of resids and resid fractions were used as solvents. Reactions of Illinois No. 6 coal with the whole resid of all three resids used resulted in similar coal conversions in the thermal reactions. However, both Maya and FHC-623 hexane solubles gave higher thermal conversions of Illinois No. 6 coal. Catalytic reactions of Illinois No. 6 favored the hexane soluble fraction as the solvent that promoted higher coal conversions in Maya and FHC-623 resids and in the case of Maya hexane solubles substantially higher conversions. Manji resid reacted differently with Illinois No. 6 coal; the Manji saturate fraction yielded the highest conversion. 
Manji whole resid and resid fractions also performed differently compared to the other two resids. The thermal reactions, in particular, resulted in low coal conversions. The Manji saturate fraction reacted with Blind Canyon coal was a particularly poor solvent for coal conversion. The catalytic reaction for whole Manji resid with Blind Canyon coal yielded low coal conversion. The hexane soluble fraction yielded the highest coal conversion for all three coal, indicating that the removal of asphaltenes from the whole resid was beneficial for Manji resid as a solvent for coal liquefaction. 


\section{References}

Kim, H., Curtis, C.W., Cronauer, D.C. and Sajkowski, D.J. "Characterization of Catalysts from Molybdenum Naphthenate," ACS Fuel Div. Prep. 34, 4, 1989, 1431. 
Table 1. Fractions of FHC-362, Maya and Manji Resid

\begin{tabular}{|c|c|c|c|c|}
\hline \% & 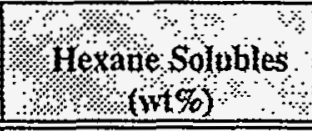 & $\begin{array}{l}\text { Toluene solubles } \\
\text { (wto\%) }\end{array}$ & $\begin{array}{l}\text { Tif Solubles } \\
\text { (wiof) }\end{array}$ & $\begin{array}{c}\text { Recotert } \\
\text { (tit } \%)\end{array}$ \\
\hline FHC-623 & $83.3 \pm 1.1$ & $14.9 \pm 0.4$ & $1.8 \pm 0.8$ & $99.9 \pm 0.9$ \\
\hline Maya & $62.9 \pm 1.1$ & $37.1 \pm 1.1$ & $0 \pm 0$ & $99.8 \pm 0.9$ \\
\hline Manji & $86.2 \pm 0.7$ & $13.9 \pm 0.7$ & $0 \pm 0$ & $99.9 \pm 0.7$ \\
\hline
\end{tabular}


Table 2. Analysis of Pittsburgh No. 8, Blind Canyon DECS-17 and Illinois No. 6 Coals $^{\mathrm{a}}$

\begin{tabular}{|c|c|c|c|}
\hline \multirow{2}{*}{\multicolumn{4}{|c|}{ 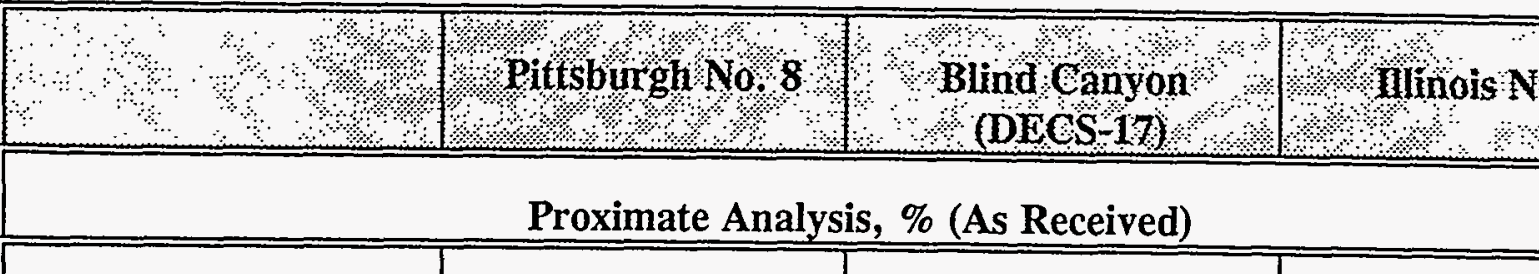 }} \\
\hline & & & \\
\hline Moisture & 1.65 & 3.74 & 7.97 \\
\hline Ash & 9.1 & 6.32 & 14.25 \\
\hline Volatile Matter & 37.2 & 45.0 & 36.86 \\
\hline \multicolumn{4}{|c|}{ Ultimate Analysis (maf basis), wt\% } \\
\hline Carbon, \% & 83.2 & 82.1 & 77.67 \\
\hline Hydrogen, $\%$ & 5.3 & 6.2 & 5.00 \\
\hline Nitrogen, $\%$ & 1.6 & 1.4 & 1.37 \\
\hline Chlorine, \% & 0.12 & 0.12 & 0.06 \\
\hline Pyritic Sulfur, \% & 1.4 & 0.02 & 2.81 \\
\hline Sulfate Sulfur, $\%$ & 0.01 & 0.01 & 0.01 \\
\hline Organic Sulfur, \% & 0.8 & 0.41 & 2.01 \\
\hline Oxygen, $\%$ & 8.83 & $\mathrm{NA}^{\mathrm{b}}$ & 13.51 \\
\hline $\mathrm{H} / \mathrm{C}$ ratio & 0.77 & 0.91 & 0.77 \\
\hline Dry Btu & 13629 & 13826 & 11951 \\
\hline Kank & HVB & HVBA & HVB \\
\hline $\begin{array}{c}\mathrm{Fe}, \%(\text { Calculated } \\
\left.\text { from } \mathrm{FeS}_{2}\right) \\
\end{array}$ & 1.23 & 0.01 & 2.46 \\
\hline
\end{tabular}

a Analyses of coal were obtained from Argonne Premium Coal Sample Bank and the Penn State Coal Sample Bank.

- $\mathrm{NA}=$ Not available 
Table 3. Liquefaction Reactions of Illinois No. $6 \mathrm{Coal}$ at $400^{\circ} \mathrm{C}^{\mathrm{a}}$

\begin{tabular}{|c|c|c|c|c|c|}
\hline ( & reaction Yoniainow. & 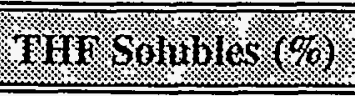 & $10110 \%$ & 6oat Conyersion $(\%)$ & Recovero $(8)$ \\
\hline Coal & Thermal & $56.8 \pm 0.6$ & $43.2 \pm 0.6$ & $62.8 \pm 0.8$ & 84.2 \\
\hline Coal & Catalytic & $56.0 \pm 1.3$ & $44.0 \pm 1.3$ & $61.8 \pm 1.6$ & 88.6 \\
\hline Hexadecane + Coal & Thermal & $44.3 \pm 0.7$ & $55.7 \pm 0.7$ & $46.7 \pm 0.9$ & 79.4 \\
\hline Hexadecane + Coal & Catalytic & $64.5 \pm 0.6$ & $35.5 \pm 0.6$ & $72.7 \pm 0.8$ & 82 \\
\hline Maya Whole Resid + Coal & Thermal & $55.8 \pm 1.1$ & $44.2 \pm 1.1$ & $61.4 \pm 1.3$ & 86.9 \\
\hline Maya Whole Resid + Coal & Catalytic & $57.3 \pm 3.0$ & $42.7 \pm 3.0$ & $63.4 \pm 3.9$ & 88.5 \\
\hline Maya Hexane Solubles + Coal & Thermal & $61.7 \pm 1.8$ & $38.3 \pm 1.8$ & $69.0 \pm 2.3$ & 98 \\
\hline Maya Hexane Solubles + Coal & Catalytic & $71.5 \pm 0.2$ & $28.5 \pm 0.2$ & $81.6 \pm 0.3$ & 93.1 \\
\hline FHC-623 Whole + Coal & Thermal & $59.7 \pm 3.3$ & $40.3 \pm 3.3$ & $66.4 \pm 4.2$ & 88.8 \\
\hline FHC-623 Whole + Coal & Catalytic & $62.6 \pm 0.6$ & $37.4 \pm 0.6$ & $70.2 \pm 0.7$ & 90.9 \\
\hline FHC-623 Hexane Solubles + Coal & Thermal & $60.5 \pm 2.2$ & $39.5 \pm 2.2$ & $67.4 \pm 2.8$ & 89.2 \\
\hline FHC-623 Hexane Solubles + Coal & Catalytic & $69.6 \pm 1.1$ & $30.4 \pm 1.1$ & $79.2 \pm 1.4$ & 88.2 \\
\hline FHC-623 Saturates + Coal & Thermal & $41.5 \pm 1.7$ & $58.5 \pm 1.7$ & $43.0 \pm 2.2$ & 93.1 \\
\hline FHC-623 Saturates + Coal & Catalytic & $51.6 \pm 3.3$ & $48.4 \pm 3.3$ & $56.1 \pm 4.2$ & 86.8 \\
\hline Manji Whole + Coal & Thermal & $58.4 \pm 0.9$ & $41.6 \pm 0.9$ & $64.8 \pm 1.1$ & 93.7 \\
\hline Manji Whole + Coal & Catalytic & $61.0 \pm 0.6$ & $34.0 \pm 0.6$ & $68.1 \pm 0.8$ & 97.2 \\
\hline
\end{tabular}


Table 3. Liquefaction Reactions of mlinois No. 6 Coal at $400^{\circ} \mathrm{C}^{\mathrm{a}}$ (continued)

\begin{tabular}{|c|c|c|c|c|c|}
\hline (3) 1 Reactant:? & Readron conuition & Tur solubles $(\%)$ & $10 \mathrm{M}\left(x_{0}\right)$ & Goal romkasion $(\%)$ & Recoyery $(\%)$ \\
\hline Manji Hexane Solubles + Coal & Thermal & $49.7 \pm 1.3$ & $50.3 \pm 1.3$ & $53 . \pm 1.6$ & 86.7 \\
\hline Manji Hexane Solubles + Coal & Catalytic & $58.8 \pm 1.3$ & $41.2 \pm 1.3$ & $65.3 \pm 1.8$ & 81 \\
\hline Manji Saturates + Coal & Thermal & $48.8 \pm 0.1$ & $51.2 \pm 0.1$ & $52.4 \pm 0.2$ & 96.1 \\
\hline Manji Saturates + Coal & Catalytic & $63.2 \pm 1.2$ & $36.8 \pm 1.2$ & $70.9 \pm 1.6$ & 96.1 \\
\hline
\end{tabular}

a Reaction Conditions: $400^{\circ} \mathrm{C}, 30 \mathrm{~min}, 8.7 \mathrm{MPa} \mathrm{H}_{2}$ pressure at ambient temperature, agitated at $400 \mathrm{rpm}, 1000$ ppm of Mo introduced as Mo naphthenate plus elemental sulfur. 
Table 4. Coal Conversion in the Coprocessing Reactions of Pittsburgh No. 8, DECS-17 Blind Canyon and Illinois No. 6 Coals with Manji Resid ${ }^{2}$

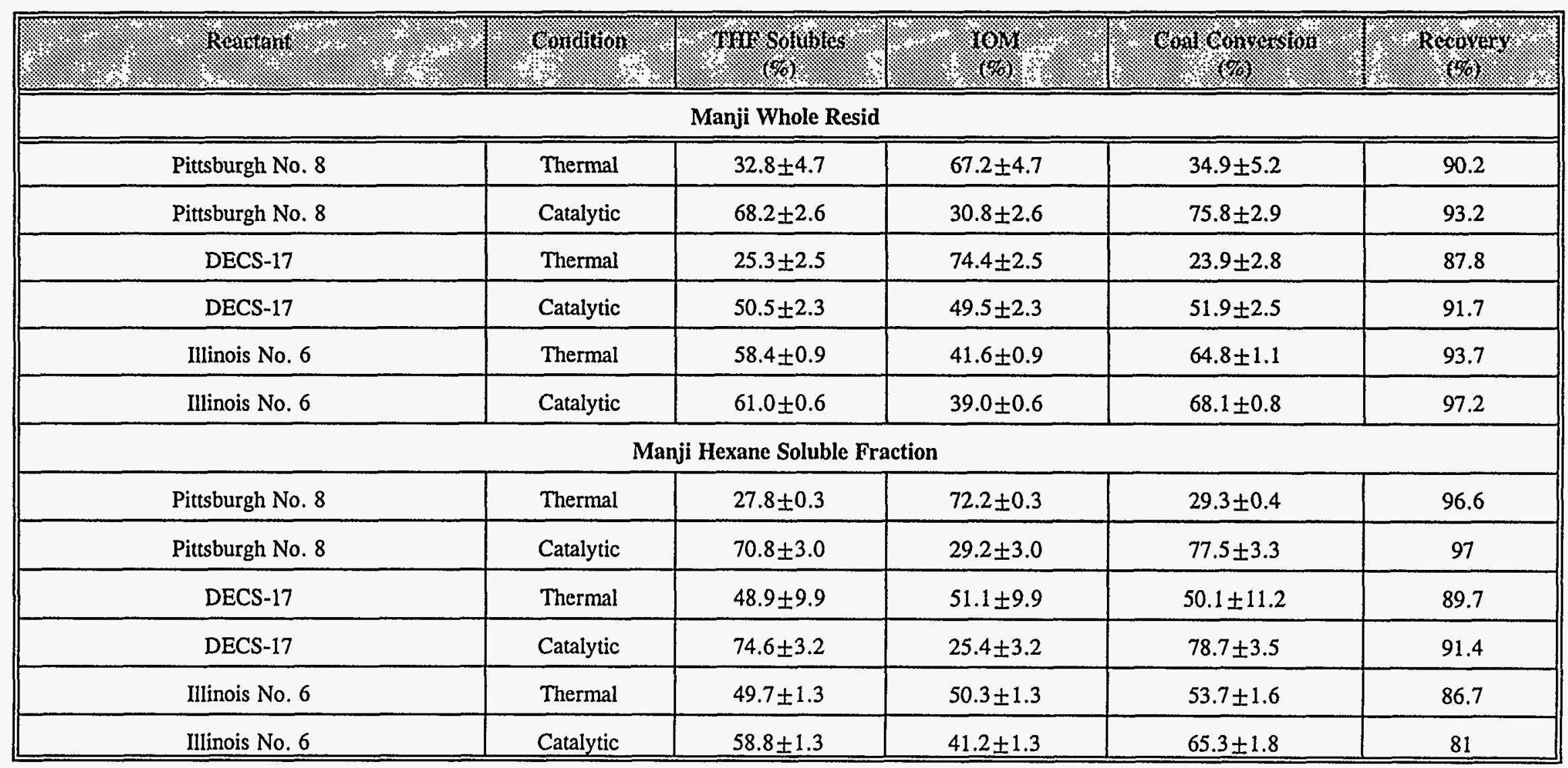


Table 4. Coal Conversion in the Coprocessing Reactions of Pittsburgh No. 8, DECS-17 Blind Canyon and Illinois No. 6 Coals with Manji Resid* (continued)

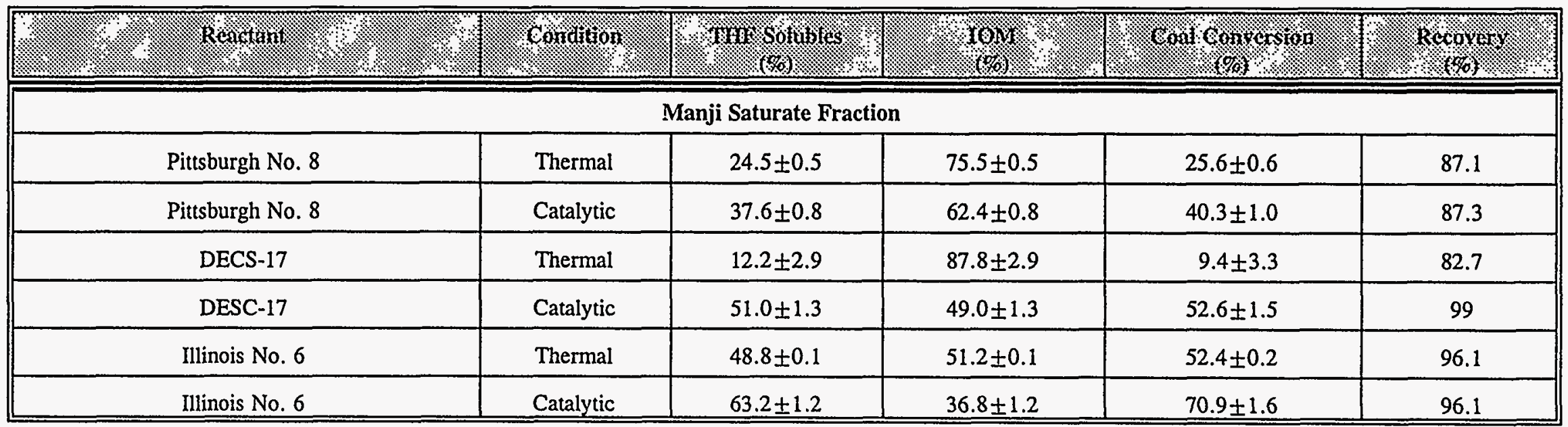

a Reaction Conditions: $400^{\circ} \mathrm{C}, 30 \mathrm{~min}, 8.7 \mathrm{MPa} \mathrm{H}_{2}$ pressure at ambient temperature, agitated at $400 \mathrm{rpm}, 1000 \mathrm{ppm}$ of Mo introduced as Mo naphthenate plus elemental sulfur. 
Table 5. Hydrogen Accepted by and Conversion of Anthracene in Reactions with Different Donor Solvents

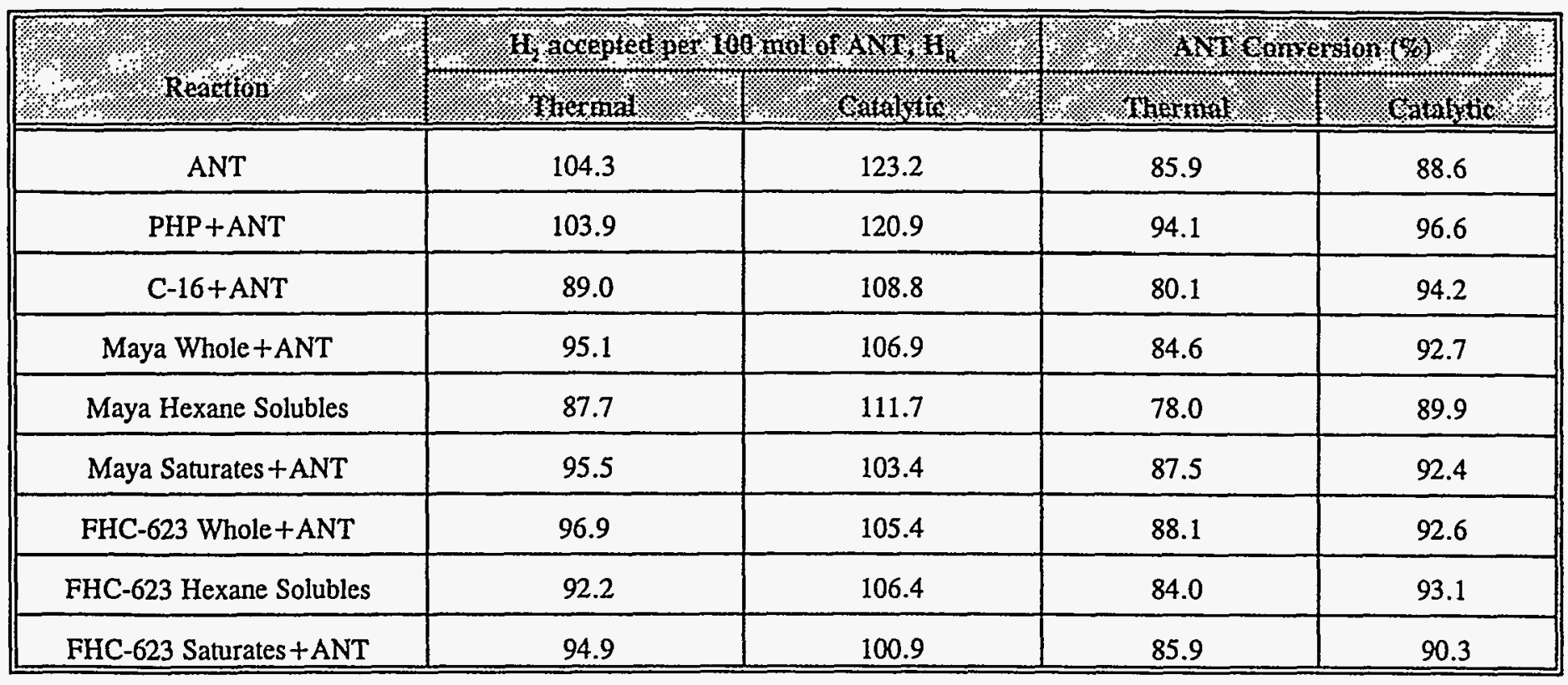


Table 6. Product Distribution of Anthracene in Reactions with Maya and FHC-623 Resids ${ }^{\mathrm{a}}$

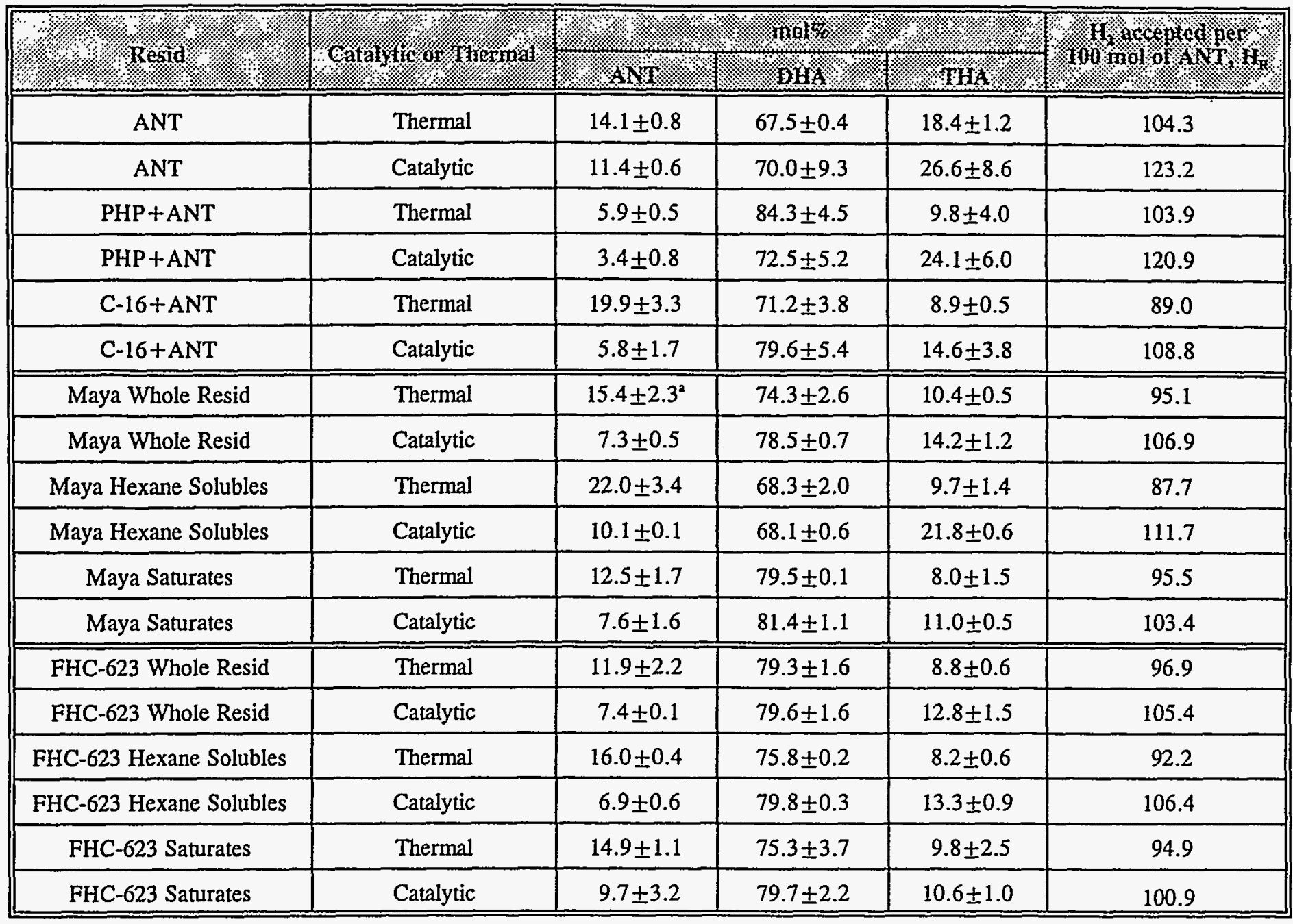

- Reaction Condition: $400^{\circ} \mathrm{C}, 30 \mathrm{~min} .8 .7 \mathrm{MPa} \mathrm{H}_{2}$ at ambient temperature.

Catalyst $=$ Mo napnthenate + sulfur, loading $1000 \mathrm{ppm}$ of Mo on a total reactant charge basis. 
Table 7. Coal Conversion in Coprocessing Reactions with Three Resids ${ }^{\mathrm{a}}$

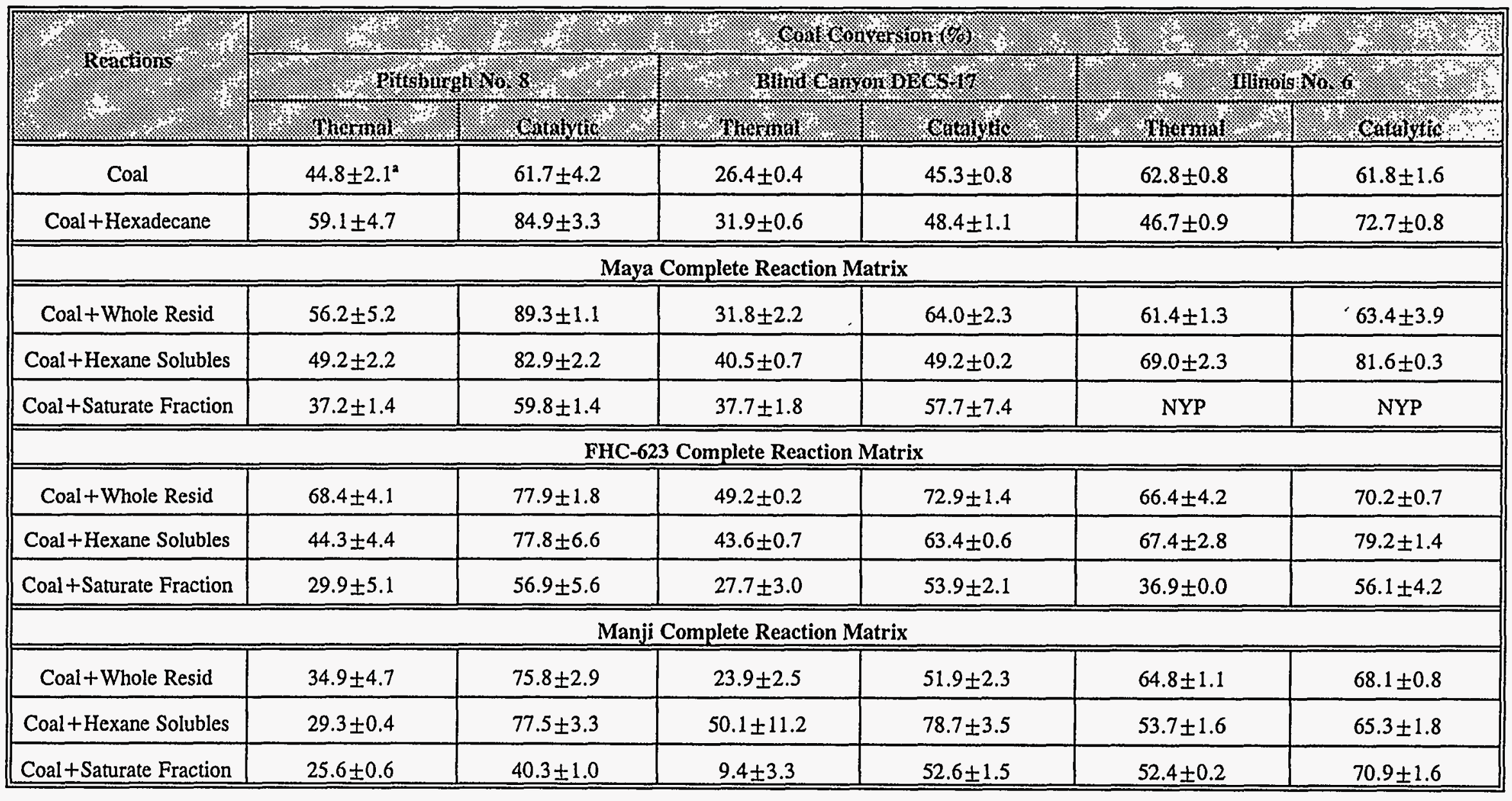

Reaction Conditions: $400^{\circ} \mathrm{C}$, reaction time $30 \mathrm{~min}$, agitated at $400 \mathrm{rpm}, 8.7 \mathrm{MPa} \mathrm{H}_{2}$ pressure at ambient temperature, 1000 ppm of Mo introduced as Mo naphthenate plus elemental sulfur.

- NYP = not yet performed 